Originally published as:

Jacob, J., Finke, A., Mielke, M.

The mglA gene and its flanking regions in Brucella: The role of mglA in tolerance to hostile environments, Fe-metabolism and in vivo persistence

(2012) International Journal of Medical Microbiology, 302 (3), pp. 148-154.

AUTHOR MANUSCRIPT. () Elsevier (2012): This is the author's version of the work. It is posted here by permission of Elsevier for personal use, not for redistribution. Some changes resulting from the publishing process, such as editing, corrections, structural formatting, and other quality control mechanisms may not be reflected in this document. Some changes may have been made to this work since being accepted for publication. A definitive version was subsequently published in International Journal of Medical Microbiology, [Volume: 302, Issue: 3, 2012] DOI: 10.1016/j.ijmm.2012.02.001 


\title{
The mglA gene and its flanking regions in Brucella: The role of mglA in tolerance to hostile environments, Fe-metabolism and in vivo persistence
}

Jens Jacob, Antje Finke, Martin Mielke

Robert Koch-Institut, Nordufer 20, 13353 Berlin, Germany

\begin{abstract}
We previously demonstrated that a spontaneous smooth small-colony variant of Brucella abortus S19 is characterized by increased in vivo persistence and the differential expression of a gene predicted to encode a galactoside transport ATP binding protein $(\mathrm{mglA})$. In order to further investigate the role of this gene in the context of its flanking regions, we analyzed the respective DNA sequences from the formerly described $B$. abortus $S 19$ as well as from avirulent $B$. neotomae $5 K 33$ and compared these with published data from other Brucella species. Deletion mutagenesis of $\mathrm{mglA}$ in the large-colony variant of $B$. abortus $S 19$ resulted in increased tolerance of the deletion mutant to a hyperosmotic (toxic), galactose-containing medium as well as to oxidative stress $\left(\mathrm{H}_{2} \mathrm{O}_{2}\right)$. Whilst the deletion mutant is characterized by reduced growth on solid $\mathrm{Fe}^{3+}$-containing minimal medium (small-colony morphology), in vivo studies in mice demonstrated statistical significant differences in the bacterial load of spleens in the pre-immune, but not in the late phase of the infection.
\end{abstract}

\section{Introduction}

Bacteria of the genus Brucella cause chronic infections in both humans and a variety of animal species. We previously characterized a spontaneous smooth small-colony variant of B. abortus S19 which demonstrates not only a reduced growth rate in vitro, but, most importantly, also a less effective clearance from spleens and livers of experimentally infected mice ( Hort et al., 2003). Using a differential approach to analyze mRNA-derived cDNA, we identified a molecular difference in the transcription of a gene predicted to encode for a formerly described galactoside transport ATP binding protein, $\mathrm{mglA}$, in the small-colony variant ( Jacob et al., 2006).

In order to further characterize the genetic basis of (adoptive) tolerance of Brucella to host immune responses, we analyzed the mglA gene and its flanking regions by means of PCR-assisted DNA 
sequencing in $\mathrm{B}$. abortus $\mathrm{S} 19$ and the avirulent $\mathrm{B}$. neotomae $5 \mathrm{~K} 33$. The comparison of these data with published mglA sequences of B. melitensis 16M (DelVecchio et al., 2002), B. abortus 2308, B. abortus 9-941 ( Halling et al., 2005), B. suis ( Paulsen et al., 2002), B. canis (Wattam et al., 2009), B. ovis ( Wattam et al., 2009), Brucella sp. 83/13 (Broad Institute of MIT and Harvard, Cambridge, USA, http://www.broad.mit.edu/annotation/genome/brucella_group/GenomeDescriptions.html\#Brucella_sp_ 83_13_v1), and B. microti CCM 4915 ( Audic et al., 2009) revealed various differences within these species.

To substantiate the assumption of a role of $\mathrm{mglA}$ in pathogenesis and tolerance to hostile environments, we generated a mglA deletion mutant of the formerly described ( Jacob et al., 2006) large-colony variant of $\mathrm{B}$. abortus $\mathrm{S} 19$. The behaviour of the mutant was characterized by assessing its growth rate on galactose and $\mathrm{Fe}^{3+}$-containing minimal media and the tolerance to both a hyperosmotic medium and oxidative stress. Moreover, the BALBc mouse model was used to test for in vivo behaviour.

\section{Material and methods}

\section{Bacterial strains}

B. abortus 2308, B. abortus S19, B. neotomae 5K33 ( Stoenner and Lackman, 1957) as well as B. microti CCM 4915 ( Scholz et al., 2008) were grown in trypticase soy broth (TSB) as described ( Hort et al., 2003) and were used for chromosomal DNA preparation according to the High Pure PCR Template Preparation Kit (Roche, Mannheim, Germany). Minimal basic medium (MBM) is a modification of Triple Sugar Iron (TSI) available from OXOID Ltd. (Basingstoke, UK, Cat. no. CM 277).

\section{Molecular biological techniques}

PCR was used to create overlapping PCR products of the following target genes of Brucella: nirK, nirV, nnrA, periplasmic protein precursor, mglA, and permease protein ( Fig. 1). That was performed using an UNO-Thermoblock (Biometra, Göttingen, Germany). The PCR fragments were analyzed by gel electrophoresis in 1\% BIO-RAD Ready-agarose TBE mini gel (BIO RAD Cat. no. 161-3010, $1 \mathrm{~V} / \mathrm{cm}, 24 \mathrm{~h}$ ). The cycling conditions and the complete list of primers are available on request. PCR products were sequenced with the ABI PRISM 3100 Genetic Analyzer using the PCR Cycle sequencing Big-DYE (V. 3.0) Terminator Protocol (PE Applied Biosystems, Foster City, CA, USA). The sequences were exported to and assembled, with respect to primary DNA sequence comparisons, using Sequencher (V. 4.6) DNA analysis software (Gene Code Corp., Ann Arbor, MI, USA). More detailed analysis and primer selection was done by means of MacVector Software (V. 10.6.0, Accelrys Inc., USA). 


\section{Deletion mutagenesis}

For deletion mutagenesis, a PCR fragment containing mglA was cloned into pJQ200mp18 ( Quandt and Hynes, 1993). The resulting plasmid $p 10 / 29$ was then digested by Mvl1269l/Pagl yielding $p 10 / 29$ which contained $\Delta \mathrm{mglA}$, characterized by a deletion of $460-652$ bp with respect to the intact $\mathrm{mglA}$.

Then, p10/29 ( $\triangle \mathrm{mglA}$ ) was mobilized into $\mathrm{B}$. abortus S19A strain (the large-colony variant) from $\mathrm{E}$. coli strain S17-1 (-pir) (Simon et al., 1983) by conjugation on Brain Heart Agar (BHA) for 2 days at $37^{\circ} \mathrm{C}\left(5 \% \mathrm{CO}_{2}\right.$ vol.). Transconjugants were selected on $\mathrm{BHA}$ supplemented with nalidixic acid $(5 \mu \mathrm{g} / \mathrm{ml})$, polymixin-B $(5 \mathrm{lU} / \mathrm{ml})$, and gentamicin $(50 \mu \mathrm{g} / \mathrm{ml})$. Single colonies growing on this medium were subcultured on $\mathrm{BHA}+$ antibiotics with and without $5 \%$ sucrose.

Gentamicin-resistant colonies were selected, DNA extracted (High Pure PCR Template Preparation Kit, Roche) and analyzed by PCR using mglA-specific primers to confirm the deletion of the internal Mvl1269l/Pagl fragment in mglA ( Fig. 2).

\section{In vitro tolerance assays}

In vitro tolerance assays were performed in ' $\mathrm{F} 1$-medium' consisting of $17 \mathrm{~g}$ casein peptone, $3 \mathrm{~g}$ soybean meal peptone, $2 \mathrm{~g}$ yeast extract, $49 \mathrm{~g}$ potassium acetate, $9 \mathrm{~g} \mathrm{M} 9$ minimal media salt $\mathrm{A}$, and $1.7 \mathrm{~g} \mathrm{M9}$ minimal media salt B (MP Biomedicals, Illkirch, France) per litre. The medium was adjusted to $\mathrm{pH} 7.0$ and subsequently autoclaved. Finally, the sugar content was adjusted to be $10 \mathrm{mM}$ by means of addition of sterile filtered galactose solution. $1 \times 10^{9}$ viable cells of each $B$. abortus 2308 , B. abortus S19, B. neotomae $5 \mathrm{~K} 33$, and B. abortus S19 A $\Delta$-mglA 3.14 were used to yield an initial experimental inoculum of $1 \times 10^{7} \mathrm{cells} / \mathrm{ml}$. Experiments were performed at $37^{\circ} \mathrm{C}$ under an oxygendepleted and $\mathrm{CO}_{2}$-enriched atmosphere in an anaerobic jar (Anaerocult C, Merck, Darmstadt, Germany). Survival of cells was determined by taking aliquots of $100 \mu \mathrm{l}$ each and plating on trypticase soy agar (TSA) on days 1, 3, 6, 8, and 10 ( Fig. 5).

In another set of experiments, $\mathrm{H}_{2} \mathrm{O}_{2}$ in concentrations of $(0.6,0.3,0.15,0.075 \%$ each) was added to RPMI 1640 medium to test tolerance to oxygenic stress.

Modified triple sugar iron agar (TSI, No. 227, Oxoid, Germany) was used to test for growth on this medium containing $1.8 \mathrm{~g} / \mathrm{l}(10 \mathrm{mM})$ galactose and $/ \mathrm{or} \mathrm{Fe}^{3+}$ at $37^{\circ} \mathrm{C}$ under both aerobic and microaerobic conditions. Fig. 4 shows Brucella which were grown aerobically only.

\section{In vivo behaviour of bacterial strains}

Female, 10-12 week-old BALBc mice were used for all experiments. They were raised in the breeding facilities of Charles River WIGA (Sulzfeld, Germany) under specified pathogen-free conditions. The experiments were performed in the $\mathrm{L} 3$ facilities of the Robert Koch-Institute using an IsoCage-System (Tecniplast, Hohenpeißenberg, Germany). Mice were infected with $5 \times 10^{6}$ viable Brucella each in $0.1 \mathrm{ml} \mathrm{PBS}$. Subsequently, on the days 7, 21, and 45, defined groups of 5, 5, and 8 animals, 
respectively, were sacrificed. Spleens were removed and weighed. Numbers of viable bacteria per spleen were determined by serial dilutions plated on TSA agar. For statistical analysis, Mann-Whitney test was performed by grouping bacterial counts for both strains $A$ (wild type, B. abortus S19) and $M$ $(\Delta$-mglA mutant strain, B. abortus S19 A $\Delta$-mglA 3.14) obtained on days 7,21 , and 45 of the mouse experiment.

\section{Immunohistology and cytology}

On days 7, 21, and 45 after infection, the mice were killed and the corresponding parts of spleens were removed and immersed in O.C.T. compound (Tissue Tek, Bakura, USA), and kept at $-20^{\circ} \mathrm{C}$ for histologic evaluation. Cryostat sections were fixed in acetone, treated with the respective primary antibody, anti-Brucella LPS (Difco, Detroit, MA, USA; 1:100 dil.), and diluted in PBS plus 10\% FCS for $45 \mathrm{~min}$ at room temperature in humidified air. Incubation ensued with the secondary antibody, a peroxidase-conjugated mouse anti-rabbit IgG (Dianova, Hamburg, Germany) diluted 1:100 for antiBrucella, respectively (45 min, room temperature, humidified air). Slides were covered with $100 \mu \mathrm{l}$ of the freshly prepared 3,3'-diaminobenzidine chromogen-substrate solution (Vector, Burlingame, CA, USA) containing $0.06 \%$ Tris buffer, $0.03 \% \mathrm{H}_{2} \mathrm{O}_{2}$, at $\mathrm{pH} 7.6$ for approximately 3 min. Finally, the sections were washed, counterstained with hematoxylin, and dehydrated.

\section{Results}

\section{Differences in the mglA gene and its flanking regions in the genus Brucella}

In order to further investigate formerly obtained data about mglA-related differences in B. abortus S19 variants ( Jacob et al., 2006), DNA in the respective target region of chromosome II from B. abortus S19 as well as from avirulent B. neotomae 5 K 33 and B. microti CCM 4915 was amplified and sequenced. The data for B. abortus S19 and B. neotomae 5K33 were deposited at GenBank (EU402949 and EU410469) and compared with corresponding data from publicly available sequences from B. abortus 2308 ( Chain et al., 2005), B. abortus 9-941 ( Halling et al., 2005), B. abortus S19 ( Crasta et al., 2008), B. melitensis 16M ( DelVecchio et al., 2002), B. suis ( Paulsen et al., 2002), B. ovis ( Wattam et al., 2009), B. canis (Wattam et al., 2009), Brucella sp. 83/13 (http://patricbrc.vbi.vt.edu/portal/portal/patric/Taxon?cType=taxon\&cld=520449), B. neotomae 5K33 (http://patricbrc.vbi.vt.edu/portal/portal/patric/Taxon?cType=taxon\&cld=520456) as well as with the data obtained by sequencing of the respective genes in B. microti CCM 4915, later confirmed by Audic et al. (2009).

For further comparison, the flanking genes BMEII0981 (permease), BMEll0983 (periplasmic protein precursor), BMEII0985 (operon repressor), and BMEII0986 (transcriptional regulator, nnrA), as well as BMEII0987 (nirV), and BMEII0988 (nitrate reductase precursor, nirK) were also taken into consideration. The $\mathrm{B}$. melitensis $16 \mathrm{M}$ genome was used as a reference. 
The mglA-DNA sequence of the investigated $B$. abortus $S 19$ strain was identical to the published sequence of $B$. abortus 9-941 while in $B$. abortus $2308 \mathrm{mglA}$ is truncated at amino acid (AA) position 236 ( Fig. 3) ( Chain et al., 2005). The comparison with other Brucella biovars/species revealed that B. neotomae, B. ovis, and B. microti show the most complete sequences of the mglA gene while $B$. abortus, including strain B. abortus S19, B. melitensis, B. canis, and B. suis are characterized by nucleotide deletions, resulting in the loss or exchange of amino acids at various positions ( Fig. 3). In the newly identified species Brucella sp. 83/13 (http://patricbrc.vbi.vt.edu/portal/portal/patric/Taxon?cType=taxon\&cld=520449), mglA as well as its flanking genes (operon repressor, periplasmic protein precursor, and permease) are missing ( Fig. 1, Table 1).

However, in contrast to the complete mglA gene, the avirulent B. neotomae $5 \mathrm{~K} 33$ demonstrates a large-scale nucleotide deletion of $2.2 \mathrm{~kb}$ including a partial deletion of the genes BMEII0986 and BMII0988, respectively, and a complete deletion of BMEII0987 (Baek et al., 2004) resulting in the loss of putative regulator genes (nnrA, nirK, nirV) ( Fig. 1, Table 1).

\section{Deletion mutagenesis of $\mathrm{mglA}$}

To further investigate the potential role of $\mathrm{mglA}$, we generated a $\Delta$-mglA deletion mutant of the large variant of B. abortus S19 A by allelic gene replacement ( Campos et al., 2002, Quandt and Hynes, 1993 and Pelicic et al., 1996). Successful deletion was confirmed by both PCR ( Fig. 2) and DNA sequencing (data not shown). In Fig. 2, lanes 2, 3, and 5 demonstrate the $\Delta$-mglA-specific PCR fragment of $1.4 \mathrm{~kb}$ size as a result of gene exchange, as compared to the parental strain in lanes 1,4 , and $6(1.6 \mathrm{~kb})$.

\section{Behaviour on $\mathrm{Fe}^{3+}$-containing minimal medium and tolerance to oxidative stress}

Our original investigation (Jacob et al., 2006) was initiated by the observation of a reduced growth rate of a small-colony variant of $\mathrm{B}$. abortus $\mathrm{S} 19$. We therefore characterized the growth of $\mathrm{B}$. abortus S19 A $\Delta$-mglA 3.14 on defined galactose and/or $\mathrm{Fe}^{3+}$-containing minimal media. On these media, B. abortus S19 A $\Delta$-mglA 3.14 showed a reduced growth (i.e. colony size) whenever $\mathrm{Fe}^{3+}$ was present in the medium ( Fig. 4). In addition, B. abortus S19 A $\Delta$-mgIA 3.14 was characterized by increased tolerance to $\mathrm{H}_{2} \mathrm{O}_{2}(0.3 \%$ versus $0.085 \%$, Table 2$)$ and a higher tolerance to a galactose-containing hyperosmotic (i.e. toxic) medium (F1) ( Fig. 5).

\section{In vivo behaviour}

The investigation of the in vivo behaviour of the $\Delta-\mathrm{mglA}$ mutant mainly focused on differences in the persistence of the bacteria in the late phase of infection ( Hort et al., 2003). Mice were infected with $5 \times 10^{6}$ viable bacteria of $\mathrm{B}$. abortus S19A and its isogenic mglA deletion mutant B. abortus S19 A $\Delta$ mglA 3.14, and the bacterial load was determined in spleens on days 7,21 , and 45 , respectively. While the bacterial load was similar on day 45 after infection, the infection with the mglA deletion 
mutant resulted in a slight, but significantly higher bacterial load on day 7 after infection which represents the pre-immune phase of the infection ( Fig. 6).

\section{Immunohistology and cytology}

In order to further investigate the differences in bacterial load on day 7 and day 21 , spleens of infected mice were investigated by immunohistology using a Brucella-LPS-specific antibody ( Hort et al., 2003). Histological alterations in spleens of Brucella-infected mice have been described earlier ( Hort et al., 2003) and did not differ significantly between the groups investigated in this study (data not shown).

\section{Discussion}

The persistence of bacteria in chronic infections like brucellosis may be due to (i) inadequate host responses or (ii) a specific ability of the invader to tolerate (or evade) usually effective defence mechanisms. In addition, Brucella-induced inflammatory responses in the spleens of infected animals associated with changes in the eradication kinetics of Brucella have been described ( Hort et al., 2003). In a previous paper, we demonstrated that in B. abortus $S 19$ a gene predicted to encode for a formerly described galactoside transport ATP binding protein $(\mathrm{mglA})$ is differentially expressed in small- versus large-colony variants which differ in in vivo persistence ( Jacob et al., 2006). In an attempt to further investigate the potential role of this gene locus, we analyzed mglA and its flanking regions in various members of the genus Brucella.

Sequencing of the mglA gene of both, the large- and the small-colony variants of strain B. abortus S19 revealed no differences on the DNA level when compared to the homologous genes of $\mathrm{B}$. abortus biovar 1 strain 9-941. Compared to the attenuated vaccine strain B. abortus S19, virulent B. abortus 2308, however, demonstrates an additional deletion in the mglA gene resulting in the loss of 42 amino acids at the C-terminal end at position $236 \mathrm{ff}$ ( Fig. 3). In B. melitensis, a specific difference in the mglA gene is present at amino acid position 199-205 while in B. suis and B. canis, there is a deletion of amino acids at position 214/215.

Additional differences in $\mathrm{mgl} \mathrm{A}$ and its flanking regions became prominent when compared to $\mathrm{B}$. neotomae and other members of the genus Brucella like B. ovis, B. microti, and Brucella sp. 83/13. The $B$. microti $\mathrm{mglA}$ sequence which we obtained was identical to the one from a $\mathrm{B}$. microti wholegenome sequencing project ( Audic et al., 2009) and, therefore, we did not submit our own results to NCBI.

Data obtained from the investigation of the flanking regions of $\mathrm{mglA}$, especially in putative regulatory genes ( Fig. 1, Table 1), revealed that the sequences of B. microti CCM 4915 ( Audic et al., 2009) and B. ovis are similar, not only with respect to $\mathrm{mglA}$, but also to the flanking regions. In this context, $\mathrm{B}$. ovis is of special interest because of its narrow host range and tissue tropism ( Tsolis et al., 2009), while possessing the whole mgl operon. 
In summary, B. neotomae, B. ovis, and B. microti, all characterized by reduced pathogenicity, have the most complete mglA gene sequence, while B. melitensis, B. suis, B. canis, and B. abortus are characterized by specific deletions. Taken together with differences in the flanking regions, this gene locus may thus be interesting not only for diagnostic purposes ( Table 1), but also with respect to virulence and pathogenesis. So far, the most relevant difference between the virulent and chronically persisting strain B. abortus 2308 and the vaccine strain B. abortus $\mathrm{S} 19$ has only been described for erythritol-catabolism ( Crasta et al., 2008 and Sangari et al., 2000). Most interestingly, the differences in the mglA genome region enable similar conclusions as the results of a phylogenetic 'clade' system, based on whole-genome comparisons ( Wattam et al., 2009), which describes B. ovis as an 'ancestor' from which other Brucella species may have diverged from.

The differences in the mglA sequences within the genus Brucella and the loss of regulatory genes as examplified in B. neotomae 5K33 ( Fig. 1 and Fig. 3, Table 1) can be interpreted as a result of ongoing genetic rearrangements in this region of chromosome II. Such mechanisms have been described as a cause for the generation of strain and species-specific differences within the genus Brucella ( Chain et al., 2005, Rajashekara et al., 2005 and Tsoktouridis et al., 2003).

With respect to functional consequences of differences in this gene region, it is worth mentioning that a gene in immediate neighbourhood and functionally related to $\mathrm{mglA}$, the D-galactose-binding periplasmic protein precursor (BMEII0983), has been found to be underexpressed in the attenuated vaccine strain B. melitensis Rev1 (Eschenbrenner et al., 2002) and recently in B. abortus 2308 ( Lamontagne et al., 2009). Furthermore, the gene nnrA (BMEII0986), which is an immediate neighbour of the operon and potentially involved in its regulation ( Fig. 1), has been demonstrated as a virulence factor ( Haine et al., 2006). The absence of nnrA (BMEII0986) in the avirulent B. neotomae 5K33 ( Baek et al., 2004) has now been confirmed in the context of this study (GenBank acc.no. EU410469). However, in the initial paper ( Baek et al., 2004) describing the importance of nnrA, nirV, and nirK for virulence, no data were presented for mglA. Data from hybridization studies of the virulent $B$. melitensis and the avirulent $B$. neotomae demonstrate only 2 significant differences in the genome between these organisms ( Baek et al., 2004). One is the region analyzed in more detail here, the other one is an additional, possibly Rhizobium-borne gene region ( Rajashekara et al., 2004).

There are more hints that the region around mglA may be involved in Brucella pathogenicity as the genome region upstream of mgIA has just been shown by means of DNA microarray as to be poorly expressed under laboratory conditions in B. abortus 2308 (Viadas et al., 2009) (BAB2_0941, 0942, 0943). In addition, gene norD, upstream of the operon repressor, has also been described to be involved in virulence of B. suis ( Loisel-Meyer et al., 2006).

In B. suis 1330, the gene nosZ (BRA0275) was described by proteomics ( Al Dahouk et al., 2009) as to be overexpressed during anaerobic survival.

In order to substantiate the assumption that mglA may be involved in the tolerance of Brucella to hostile environments, we generated an mglA deletion mutant of the large-colony type of $B$. abortus 
S19 A ( Jacob et al., 2006) and tested it in various in vitro and in vivo assays. The increased tolerance of the deletion mutant in a galactose-containing hyperosmotic medium ( Fig. 5) as well as to oxidative stress $\left(\mathrm{H}_{2} \mathrm{O}_{2}\right)$ ( Table 2) may be taken as a hint that the region is involved in tolerance to adverse environmental conditions ( Köhler et al., 2002 and Köhler et al., 2003).

Most interestingly, the reduced growth on $\mathrm{Fe}^{3+}$-containing minimal media (Fig. 4) revealed an in vitro phenotype of the deletion mutant that has previously been described for a spontaneous small-colony variant of B. abortus S19 ( Jacob et al., 2006).

Finally, in vivo experiments were performed in order to identify the effects of mglA deletion on in vivo persistence of Brucella. Whilst there was a significant difference in bacterial load of spleens in the preimmune phase of the infection, both the vaccine strain S19 and the mglA-deletion mutant did not differ in the amount of bacteria present in the late phase of the infection, which is characterized by their residence in NO synthase-positive macrophages.

In conclusion, mglA and its flanking regions may be useful for diagnostic purposes. In addition, deletion mutagenesis of $\mathrm{mglA}$ resulted in a small-colony phenotype on $\mathrm{Fe}^{3+}$-containing minimal medium.

The intracellular fate of various Brucella strains and mutants differing in the respective gene locus in the presence and absence of IFN- $\gamma$ is the topic of forthcoming investigations.

\section{Acknowledgements}

B. neotomae $5 \mathrm{~K} 33$ and B. microti CCM 4915 were both obtained from AFFSA (Maison-Alfort, France). Brucella sp. 83/13 was provided by VLA (Weybridge, UK). 


\section{References}

Al Dahouk, S., Loisel-Meyer, S., Scholz, H.C., Tomaso, H., Kersten, M., Harder, A., Neubauer, H., Köhler, S., Jubier-Maurin, V., 2009. Proteomic analysis of Brucella suis under oxygen deficiency reveals flexibility in adaptive expression of various pathways. Proteomics 9, 3011-3021.

Audic, S., Lescot, M., Claverie, J.M., Scholz, H.C., 2009. Brucella microti : the genome sequence of an emerging pathogen. BMC Genomics 10, 18. Baek, S.H., Rajashekara, G., Splitter, G.A., Shapleigh, J.P., 2004. Denitrification genes regulate Brucella virulence in mice. J. Bacteriol. 186, 6025-6031. Campos, E., Cravero, S.L., Delgui, L., Mora, I., Kahn, N., Arese, A.I., Rossetti, O.L., 2002. Brucella abortus INTA2, a novel strain 19 (Delta)bp26::luc (Delta)bmp18 double mutant lacking drug resistance markers. Vet. Microbiol. 87, 1-13.

Chain, P.S., Comerci, D.J., Tolmasky, M.E., Larimer, F.W., Malfatti, S.A., Vergez, L.M., Aguero, F., Land, M.L., Ugalde, R.A., Garcia, E., 2005. Whole-genome analyses of speciation events in pathogenic Brucellae. Infect. Immun. 73, 8353-8361.

Crasta, O.R., Folkerts, O., Fei, Z., Mane, S.P., Evans, C., Martino-Catt, S., Bricker, B., Yu, G., Du, L., Sobral, B.W., 2008. Genome sequence of Brucella abortus vaccine strain $S 19$ compared to virulent strains yields candidate virulence genes. PLoS ONE 3, e2193. DelVecchio, V.G., Kapatral, V., Elzer, P., Patra, G., Mujer, C.V., 2002. The genome of Brucella melitensis . Vet. Microbiol. 90, 587-592. Eschenbrenner, M., Wagner, M.A., Horn, T.A., Kraycer, J.A., Mujer, C.V., Hagius, S., Elzer, P., DelVecchio, V.G., 2002. Comparative proteome analysis of Brucella melitensis vaccine strain Rev 1 and a virulent strain, 16M. J. Bacteriol. 184, 4962-4970.

Haine, V., Dozot, M., Dornand, J., Letesson, J.J., De Bolle, X., 2006. NnrA is required for full virulence and regulates several Brucella melitensis denitrification genes. J. Bacteriol. 188, 1615-1619.

Halling, S.M., Peterson-Burch, B.D., Bricker, B.J., Zuerner, R.L., Qing, Z., Li, L.L., Kapur, V., Alt, D.P., Olsen, S.C., 2005. Completion of the genome sequence of Brucella abortus and comparison to the highly similar genomes of Brucella melitensis and Brucella suis . J. Bacteriol. 187, 2715-2726. Hort, G.M., Weisenburger, J., Borsdorf, B., Peters, C., Banai, M., Hahn, H., Jacob, J., Mielke, M.E., 2003. Delayed type hypersensitivity-associated disruption of splenic periarteriolar lymphatic sheaths coincides with temporary loss of IFN-gamma production and impaired eradication of bacteria in Brucella abortus - infected mice. Microbes Infect. 5, 95-106.

Jacob, J., Hort, G.M., Overhoff, P., Mielke, M.E., 2006. In vitro and in vivo characteri- zation of smooth small colony variants of Brucella abortus S19. Microbes Infect. 8, 363-371.

Köhler, S., Ekaza, E., Paquet, J.Y., Walravens, K., Teyssier, J., Godfroid, J., Liautard, J.P., 2002. Induction of dnaK through its native heat shock promoter is necessary for intramacrophagic replication of Brucella suis . Infect. Immun. 70, 1631-1634.

Köhler, S., Michaux-Charachon, S., Porte, F., Ramuz, M., Liautard, J.P., 2003. What is the nature of the replicative niche of a stealthy bug named Brucella . Trends Microbiol. 11, 215-219.

Lamontagne, J., Forest, A., Marazzo, E., Denis, F., Butler, H., Michaud, J.F., Boucher, L., Pedro, I., Villeneuve, A., Sitnikov, D., Trudel, K., Nassif, N., Boudjelti, D., Tomaki, F., Chaves-Olarte, E., 
Guzman-Verri, C., Brunet, S., Cote-Martin, A., Hunter, J., Moreno, E., Paramithiotis, E., 2009. Intracellular adaptation of Brucella abortus . J. Proteom. Res. 8, 1594-1609.

Loisel-Meyer, S., Jimenez de Bagues, M.P., Basseres, E., Dornand, J., Köhler, S., Liau- tard, J.P., Jubier-Maurin, V., 2006. Requirement of norD for Brucella suis virulence in a murine model of in vitro and in vivo infection. Infect. Immun. 74, 1973-1976.

Paulsen, I.T., Seshadri, R., Nelson, K.E., Eisen, J.A., Heidelberg, J.F., Read, T.D., Dodson, R.J., Umayam, L., Brinkac, L.M., Beanan, M.J., Daugherty, S.C., Deboy, R.T., Durkin, A.S., Kolonay, J.F., Madupu, R., Nelson, W.C., Ayodeji, B., Kraul, M., Shetty, J., Malek, J., Van Aken, S.E., Riedmuller, S., Tettelin, H., Gill, S.R., White, O., Salzberg, S.L., Hoover, D.L., Lindler, L.E., Halling, S.M., Boyle, S.M., Fraser, C.M., 2002. The Brucella suis genome reveals fundamental similarities between animal and plant pathogens and symbionts. Proc. Natl. Acad. Sci. USA 99, 13148-13153.

Pelicic, V., Reyrat, J.-M., Gicquel, B., 1996. Positive selection of allelic exchange mutants in Mycobacterium tuberculosis BCG . FEMS Microbiol. Lett. 144, 141-166.

Quandt, J., Hynes, M.F., 1993. Versatile suicide vectors which allow direct selection for gene replacement in Gram-negative bacteria. Gene 127, 15-21.

Rajashekara, G., Glasner, J.D., Glover, D.A., Splitter, G.A., 2004. Comparative whole- genome hybridization reveals genomic islands in Brucella species. J. Bacteriol. 186, 5040-5051.

Rajashekara, G., Glover, D.A., Krepps, M., Splitter, G.A., 2005. Temporal analysis of pathogenic events in virulent and avirulent Brucella melitensis infections. Cell. Microbiol. 7, 1459-1473.

Sangari, F.J., Aguero, J., Garcia-Lobo, J.M., 2000. The genes for erythritol catabolism are organized as an inducible operon in Brucella abortus. Microbiology 146, 487-495.

Scholz, H.C., Hubalek, Z., Sedlacek, I., Vergnaud, G., Tomaso, H., AlDahouk, S., Melzer, F., Kämpfer, P., Neubauer, H., Cloeckart, A., Marquart, M., Zygmunt, M.S., What- more, A.M., Falsen, E., Bahn, P., Göllner, C., Pfeffer, M., Huber, B., Busse, H.J., 154 J. Jacob et al. / International Journal of Medical Microbiology 302 (2012) 148- 154

Nöckler, K., 2008. Brucella microti sp. nov., isolated from the common vole Micro- tus arvalis . Int. J. Syst. Evol. Microbiol. 58, 375-382.

Simon, R., Priefer, U., Pühler, A., 1983. A broad host range mobilisation system for in vitro genetic engineering transposon mutagenesis in Gram-negative bacteria. BioTechnology 1, 784-791.

Stoenner, H.G.L., Lackman, D.B., 1957. A new species of Brucella islated from the desert wood rat, Neotoma lepida Thomas. Am. J. Vet. Res. 18, 947-951.

Tsoktouridis, G., Merz, C.A., Manning, S.P., Giovagnoli-Kurtz, R., Williams, L.E., Mujer, C.V., Hagius, S., Elzer, P., Redkar, R.J., Patra, G., DelVecchio, V.G., 2003. Molecular characterization of Brucella abortus chromosome II recombination. J. Bacteriol. 185, 6130-6136.

Tsolis, R.M., Seshadri, R., Santos, R.L., Sangari, F.J., Lobo, J.M., de Jong, M.F., Ren, Q., Myers, G., Brinkac, L.M., Nelson, W.C., Deboy, R.T., Angiuoli, S., Khouri, H., Dimitrov, G., Robinson, J.R., Mulligan, S., Walker, R.L., Elzer, P.E., Hassan, K.A., Paulsen, I.T., 2009. Genome degradation in Brucella ovis corre- sponds with narrowing of its host range and tissue tropism. PLoS ONE 4, e5519. Viadas, F., Rodriguez, M.C., Garcia-Lobo, J.M., Sangari, F.J., Lopez-Goni, I., 2009. Con- struction and evaluation of an ORFeome-based Brucella whole-genome DNA Microarray. Microb. Pathog. 47, 189195. 
Wattam, A.R., Williams, K.P., Snyder, E.E., Almeida Jr., N.F., Shukla, M., Dickerman, A.W., Crasta, O.R., Kenyon, R., Lu, J., Shallom, J.M., Yoo, H., Ficht, T.A., Tsolis, R.M., Munk, C., Tapia, R., Han, C.S., Detter, J.C., Bruce, D., Brettin, T.S., Sobral, B.W., Boyle, S.M., Setubal, J.C., 2009. Analysis of ten Brucella genomes reveals evidence for horizontal gene transfer despite a preferred intracellular lifestyle. J. Bacteriol. 191, 3569-3579.

\section{Tables and Figures}

Figure 1. $\mathrm{mglA}$ in the context of its flanking genes in chromosome II of B. melitensis $16 \mathrm{M}, \mathrm{B}$. abortus, B. neotomae, and Brucella sp. 83/13 (blue arrows indicate identical genes, red arrows indicate naturally deleted genes, slightly red arrows indicate partly deleted genes). (For interpretation of the references to color in this figure legend, the reader is referred to the web version of this article.)

\section{AA exchanges at p.199-205}

\section{Brucella melitensis $16 \mathrm{M}$}

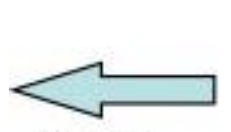

BMEII0981 sugar ABC transporter, permeat TP binding prote e protein

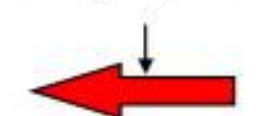

BMEII0982

Galactoside transpor mglA

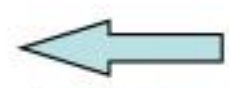

BMEIIOSB3

D-galactoside binding BMEII0985

periplasmic binding operon

periplasmic
protein precursor repressor

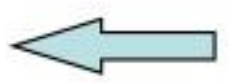

Deletion (B. abortus .2308) (AA

p. $236 \mathrm{ff}$.) or frameshift mutation

(B.abortus S19, B.abortus 9 -

941 etc.)

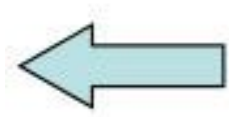

BAB2_0936

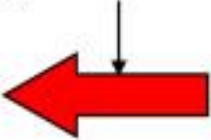

BAB2_0937

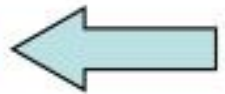

BAB2 2_0938
Brucella abortus

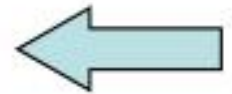

BAB2_0940

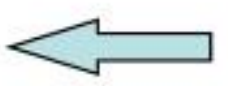

BMEIIO986

nnrA

, transcriptiona

regulator

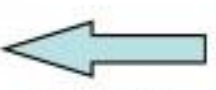

BMEIIOSB7 nirV precursor

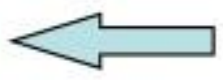

BMEIIOSB8 nirk nitrite reductase precursor

\section{Brucella neotomae $5 K 33$}

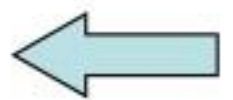

BAB2_0941

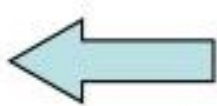

BAB2_0942

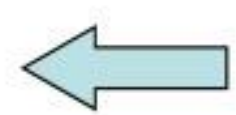

BAB2_0943
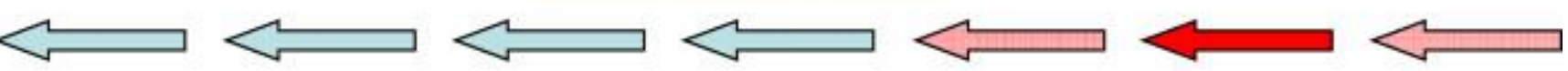

\section{Brucella $83 / 13$}
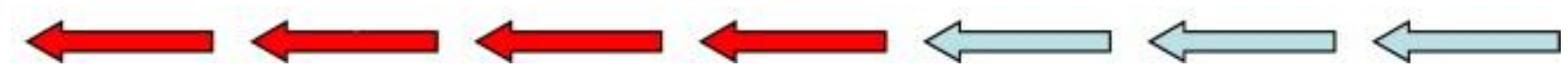
Figure 2. PCR-assisted $\mathrm{mglA}$ fragment length analysis of DNA from wild type and deletion mutants of B. abortus S19. Lanes 1, 4, 6: wild type; lanes 2, 3, 5: B. abortus S19 A $\Delta$-mglA 3.14 mutant.

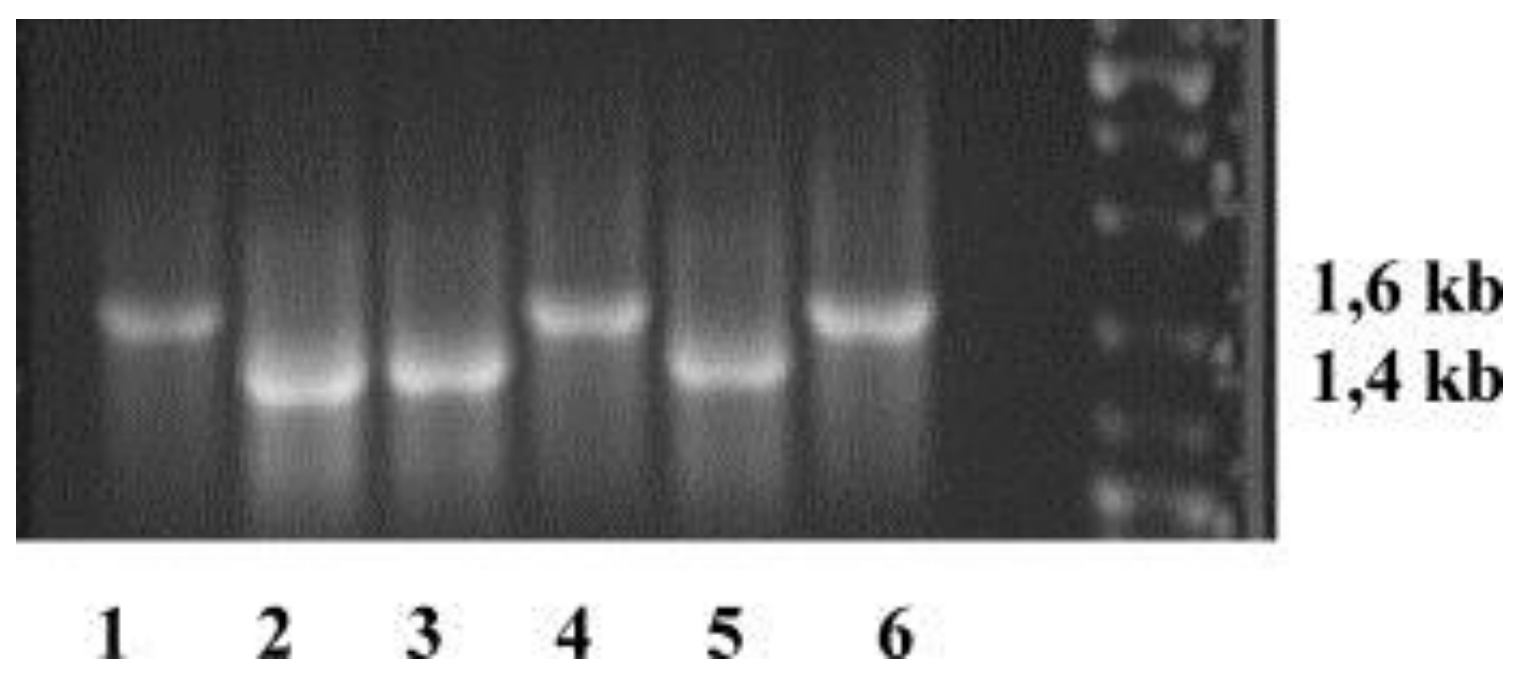


Figure 3. Formatted alignment of amino acid sequences of $\mathrm{mglA}$ from $\mathrm{B}$. neotomae $5 \mathrm{~K} 33$, B. ovis ATCC25840 (BOV_A0241), B. microti CCM 4915, B. canis ATCC 23365 (BCAN_B0267), B. suis 1330 (BRA0266), B. melitensis 16M (BMEII0982), B. abortus 9-941 (BruAb2_0914), B. abortus 2308 (BAB2_0937), and B. abortus S19 (GenBank acc.no. EU402949).

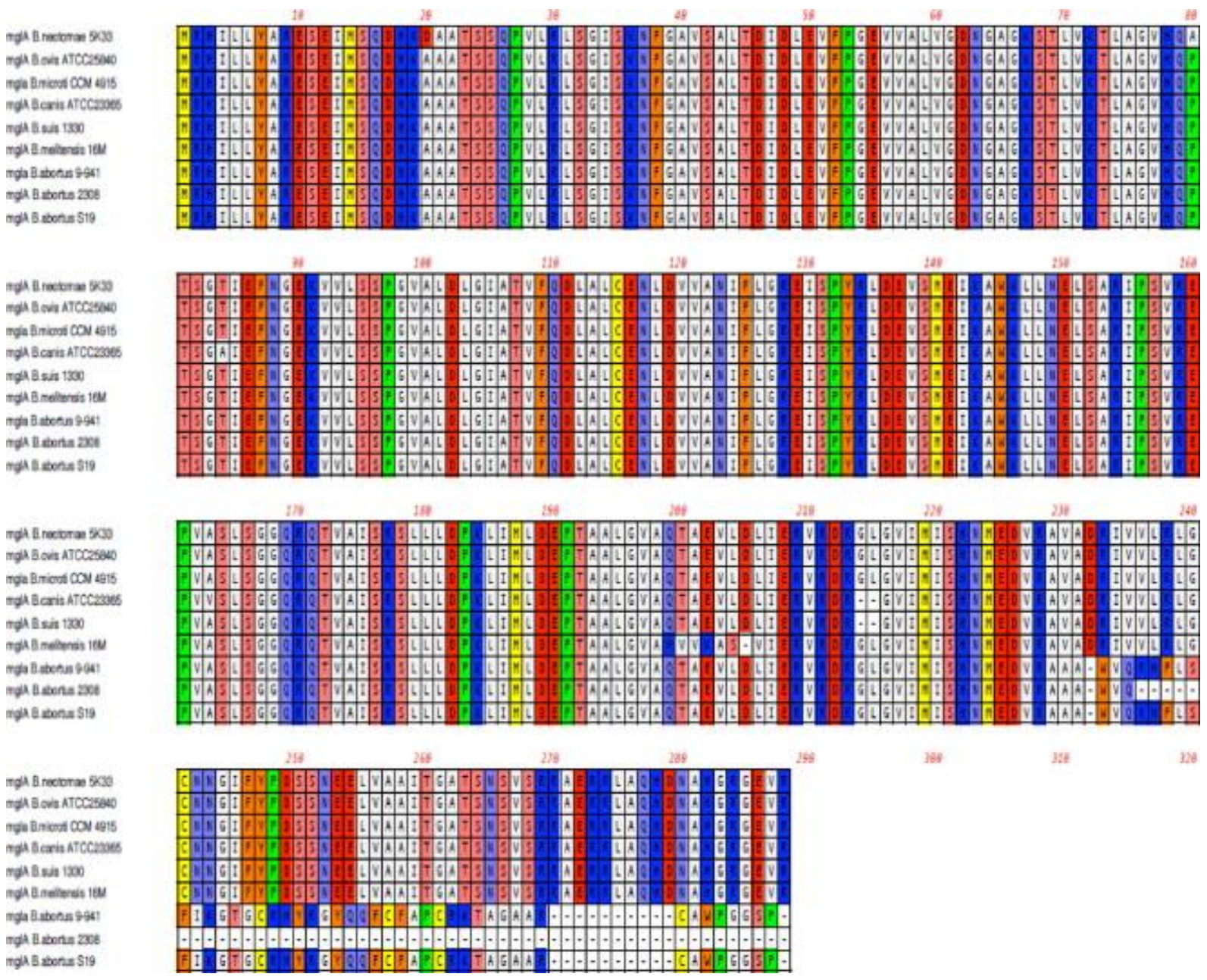


Figure 4. Growth characteristics of B. abortus 2308, B. abortus S19A, and B. abortus S19A $\Delta$-mglA 3.14 on galactose $/ \mathrm{Fe}^{3+}$-containing minimal medium under aerobic conditions. Equivalent numbers of B. abortus 2308 , B. abortus S19, and the corresponding mglA deletion mutant (B. abortus $\mathrm{S} 19 \Delta$-mglA 3.14) were grown on various defined media: (a) minimal basic medium (MBM), (b) minimal basic medium +10 mmol galactose, (c) minimal basic medium $+1 \mathrm{mmol} \mathrm{Fe}^{3+}$, (d) minimal basic medium + (galactose $\left./ \mathrm{Fe}^{3+}\right)$, and (e) minimal basic medium + $10 \mathrm{mmol}$ erythritol. Differences in erythritol metabolism have been described for both B. abortus 2308 and B. abortus S19 ( Crasta et al., 2008 and Sangari et al., 2000).

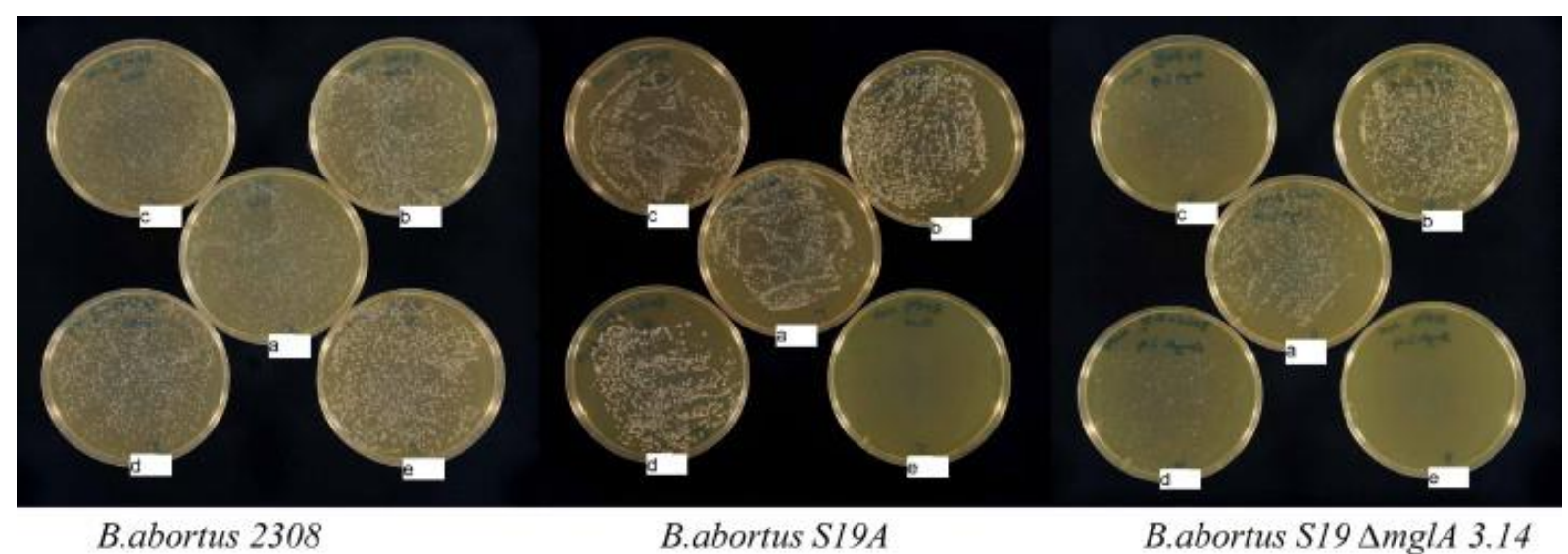


Figure 5. Survival of B. abortus S19 A, B. abortus S19 A $\Delta$-mglA 3.14, and B. neotomae $5 \mathrm{~K} 33$ in hyperosmotic medium $\mathrm{F} 1$ with and without $10 \mathrm{mM}$ galactose. A representative experiment out of 3 independent experiments using triplicates each is presented. Statistical analysis (Mann-Whitney $U$ test) revealed that differences in growth kinetics between B. abortus S19 A and B. abortus S19 A $\Delta$ mglA 3.14 were statistically significant on days 6 and 8 both in the presence of galactose $(d 6$, $p=0.0003 ; d 8, p=0.0004)$ and without galactose in the medium $(d 6, p=0.0006, d 8, p<0.0001)$.

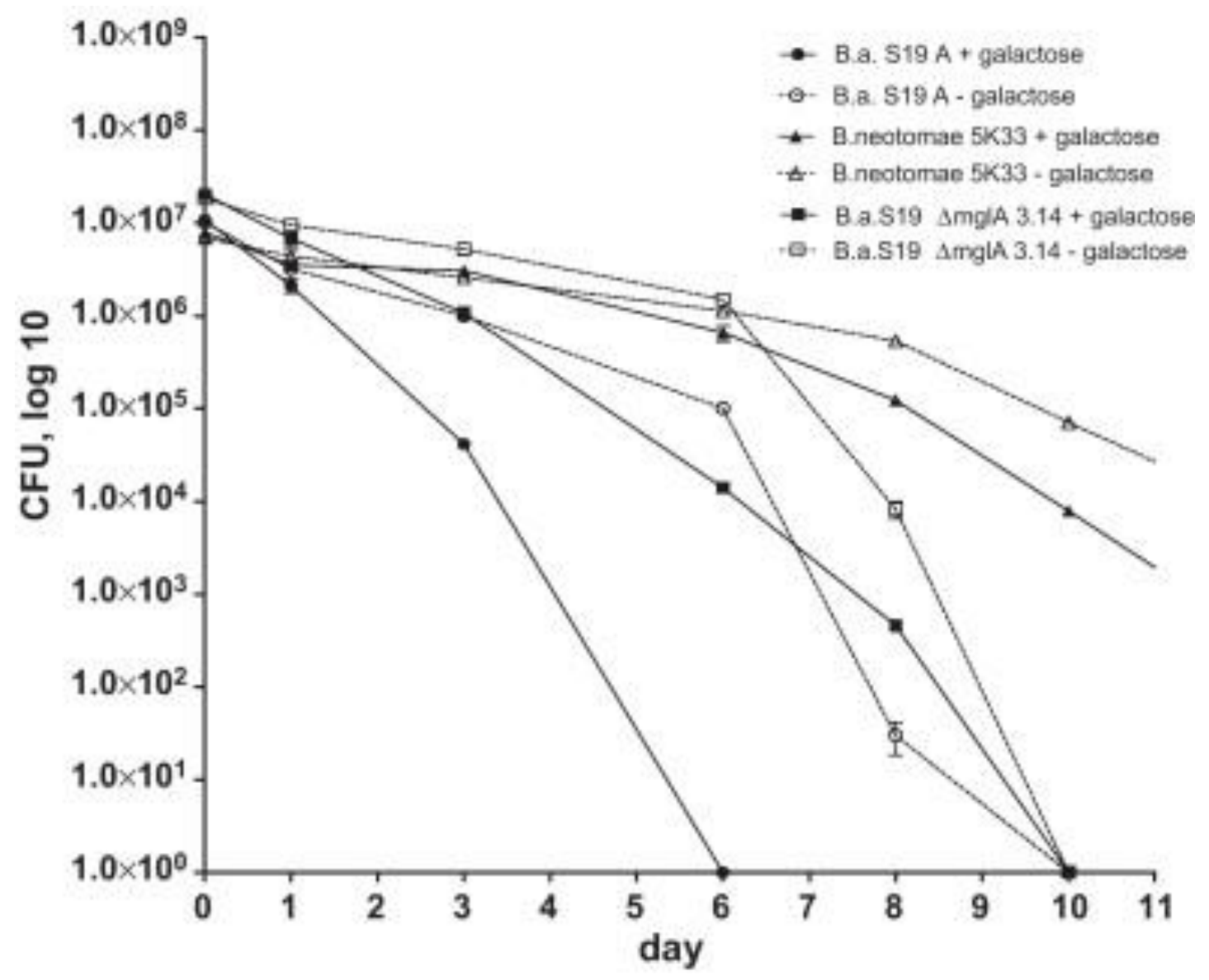


Figure 6. Kinetics of bacterial eradication in spleens of BALBc mice infected i.v. with $5 \times 10^{6} \mathrm{~B}$. abortus S19A resp. B. abortus S19A $\Delta$-mglA 3.14 (mutant strain). On days 7, 21, and 45 after infection, mice were sacrificed, spleens were homogenized, and bacterial loads were determined by plating of serial dilutions on TSA. Statistical analysis (Mann-Whitney $U$ test): (day 7, $p=0.016$; day $21, p=0.032$ ).

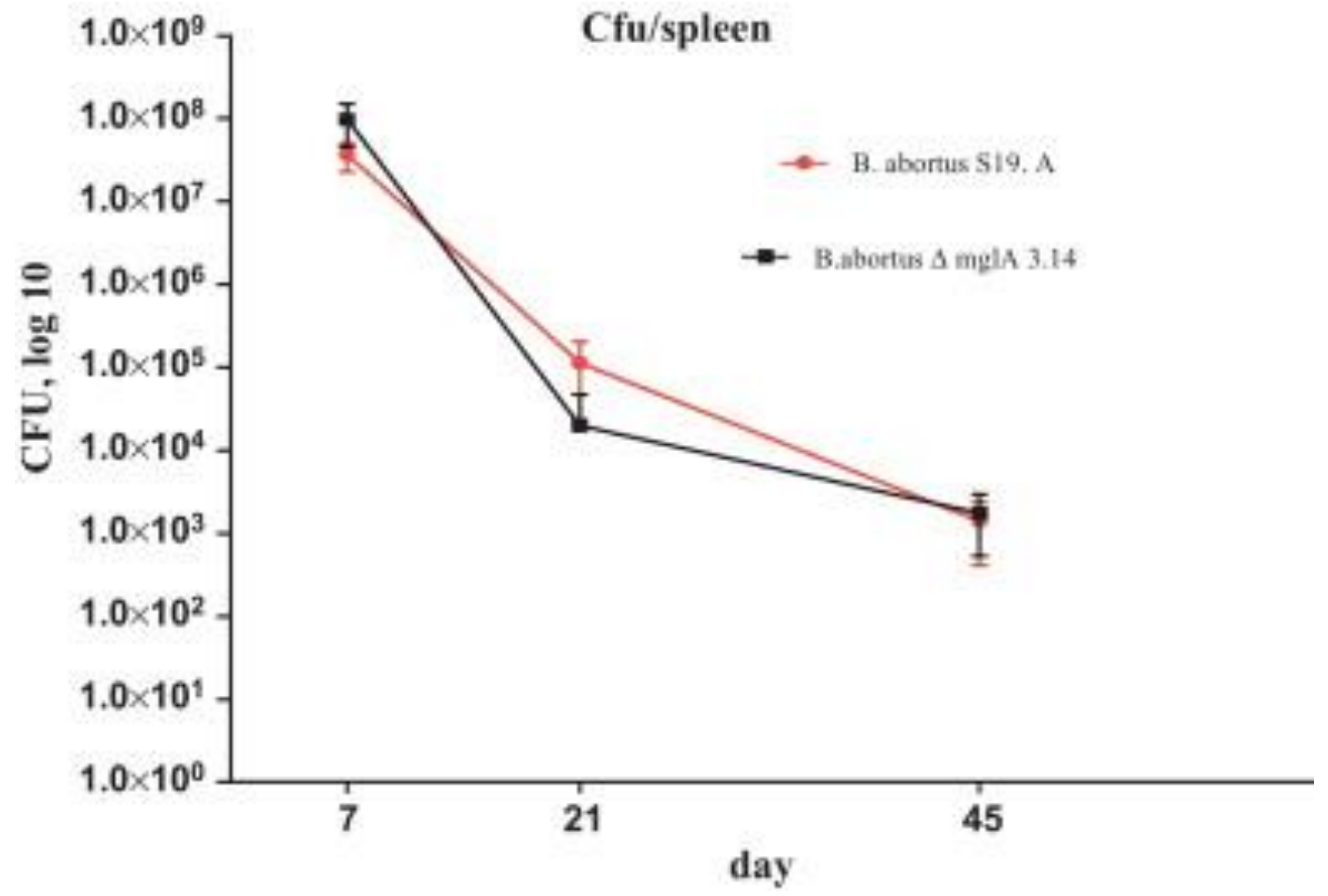


Table 1. Differences in $\mathrm{mglA}$ and its flanking regions in the genus Brucella. $A A$, amino acid; $p$, position.

Genes

Species

B.

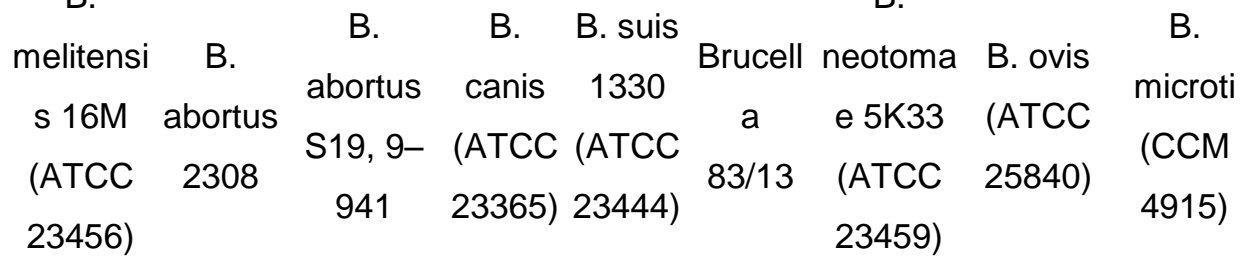

\begin{tabular}{|c|c|c|c|c|c|c|c|c|c|}
\hline \multirow{4}{*}{$\mathrm{mglA}$} & \multirow{4}{*}{$\begin{array}{l}\text { AA } \\
\text { exchang } \\
\text { e p. } \\
\text { 199-205 }\end{array}$} & \multirow{2}{*}{$\begin{array}{l}\text { Deletio } \\
\text { n at AA } \\
\text { p. } 236\end{array}$} & \multicolumn{2}{|c|}{ AA } & AA & \multirow{4}{*}{$\begin{array}{l}\text { Delete } \\
\text { d }\end{array}$} & \multirow{4}{*}{$\begin{array}{l}\text { Complet } \\
\text { e gene }\end{array}$} & \multirow{4}{*}{$\begin{array}{l}\text { Complet } \\
\text { e gene }\end{array}$} & \multirow{4}{*}{$\begin{array}{l}\text { Complet } \\
\text { e gene }\end{array}$} \\
\hline & & & $\begin{array}{l}\text { Frameshi } \\
\mathrm{ft} \text { at } \mathrm{AA}\end{array}$ & $\begin{array}{l}\text { deletio } \\
\mathrm{n} \mathrm{p.}\end{array}$ & $\begin{array}{l}\text { deletio } \\
\mathrm{n} \mathrm{p.}\end{array}$ & & & & \\
\hline & & & p. $236 \mathrm{ff}$. & $214-$ & $214-$ & & & & \\
\hline & & & & 215 & 215 & & & & \\
\hline nnrA/nirK/nir & & + & + & + & + & & - & & \\
\hline V & & & + & + & + & + & 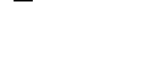 & + & + \\
\hline
\end{tabular}

Table 2. Tolerance of B. abortus 2308, B. abortus S19, and B. abortus S19 $\Delta \mathrm{mglA} 3.14$ to $\mathrm{H}_{2} \mathrm{O}_{2}$. The results show the $\mathrm{H}_{2} \mathrm{O}_{2}$ concentrations tolerated by the respective strain in the medium.

\section{Tolerance to $\mathrm{H}_{2} \mathrm{O}_{2}$}

B. abortus $2308 \quad 0.3 \pm 0 \%$

B. abortus S19 Gr. A $0.085 \pm 0.033 \%$

B. abortus S19 $\Delta \mathrm{mglA} 0.3 \pm 0 \%$ 